\title{
Different reaction mechanisms for cis- and trans-prenyltransferases
}

\author{
Yen-Pin Lu ${ }^{\mathrm{a}}$, Hun-Ge Liu ${ }^{\mathrm{b}}$, Po-Huang Liang ${ }^{\mathrm{a}, \mathrm{b}, *}$ \\ a Institute of Biochemical Sciences, National Taiwan University, Taipei 106, Taiwan, ROC \\ ${ }^{\mathrm{b}}$ Institute of Biological Chemistry, 128 Academia Rd. sec. 2, Academia Sinica, Taipei 115, Taiwan, ROC
}

\section{A R T I C L E I N F O}

\section{Article history:}

Received 24 November 2008

Available online 25 December 2008

\section{Keywords:}

Isoprenoid

Prenyltransferase

Reaction mechanism

Sequential

Concerted

\begin{abstract}
A B S T R A C T
Octaprenyl diphosphate synthase (OPPs) and undecaprenyl diphosphate synthases (UPPs) catalyze consecutive condensation reactions of farnesyl diphosphate (FPP) with 5 and 8 isopentenyl diphosphate (IPP) to generate $C_{40}$ and $C_{55}$ products with trans- and cis-double bonds, respectively. In this study, we used IPP analogue, 3-bromo-3-butenyl diphosphate (Br-IPP), in conjunction with radiolabeled FPP, to probe the reaction mechanisms of the two prenyltransferases. Using this alternative substrate with electron-withdrawing bromo group at the $\mathrm{C} 3$ position to slow down the condensation step, trapping of farnesol in the OPPs reaction from radiolabeled FPP under basic condition was observed, consistent with a sequential mechanism. In contrast, UPPs reaction yielded no farnesyl carbocation intermediate under the same condition with radiolabeled FPP and Br-IPP, indicating a concerted mechanism. Our data demonstrate the different reaction mechanisms for cis- and tran-prenyltransferases although they share the same substrates. (C) 2008 Elsevier Inc. All rights reserved.
\end{abstract}

Isoprenoids are an extensive group of natural products with different carbon skeletons constructed from the five-carbon isopentenyl diphosphate (IPP) [1]. Over 55,000 isoprenoid compounds have been identified, which are responsible for a variety of biological functions in bacteria, archaea, and eukaryotes [2,3]. Isoprenoids are synthesized by a large group of enzymes named prenyltransferases. A class of prenyltransferases catalyze chain elongation of an allylic diphosphate substrate [e.g. farnesyl diphosphate (FPP)] with specific numbers of IPP via $1^{\prime}-4$ condensation reactions to generate linear products with defined chain lengths [4,5]. $C_{15}$ FPP itself is produced by coupling of two IPP with its isomer dimethylallyl diphosphate through the $C_{10}$ geranyl diphosphate (GPP) catalyzed by farnesyl diphosphate synthase (FPPs) [6].

Based on the stereochemistry of the double bonds formed during IPP condensation reactions, these prenyltransferases are classified as trans- and cis-types. Octaprenyl diphosphate synthase (OPPs) that catalyzes the condensation reactions of FPP with 5 IPP is trans-type and its long-chain $\mathrm{C}_{40}$ product constitutes the side chain of ubiquinone [7,8]. On the other hand, undecaprenyl diphosphate synthase (UPPs) that catalyzes condensation reactions

\footnotetext{
Abbreviations: IPP, isopentenyl diphosphate; FPP, farnesyl diphosphate; GPP, geranyl diphosphate; FPPs, farnesyl diphosphate synthase; OPPs, octaprenyl diphosphate synthase; UPPs, undecaprenyl diphosphate synthase; UPP, undecaprenyl diphosphate; TLC, thin layer chromatography; FOH, farnesol; Br-IPP, 3Bromo-3-butenyl diphosphate; Hepes, 4-(2-hydroxyethyl)-1-piperazineethanesulfonic acid

* Corresponding author. Address: Institute of Biological Chemistry, 128 Academia Rd. sec. 2, Academia Sinica, Taipei 115, Taiwan, ROC. Fax: +886 227889759.

E-mail address: phliang@gate.sinica.edu.tw (P.-H. Liang).
}

of FPP with 8 IPP is cis-type and its long-chain $C_{55}$ product serves as a lipid carrier to transport the carbohydrates across the cell membrane for the biosynthesis of bacterial peptidoglycan $[9,10]$. Thus, UPPs can serve as a target for new antibiotics. Selective inhibitors of $S$. peumoniae UPPs and their antibacterial activities have been reported [11].

Cis- and trans-prenyltransferases may utilize different strategies for catalysis although they share the same substrates FPP and IPP. This is suggested by the lack of sequence similarity between the two groups of prenyltransferases [12,13]. The known crystal structures show that trans-prenyltransferases use two conserved DDXXD motifs to coordinate with two or three $\mathrm{Mg}^{2+}$ ions for binding with the diphosphate group of the allylic substrate [14-16], whereas an Asp in the conserved P-loop of cis-type prenyltransferases (D26 in E. coli UPPs) plays the $\mathrm{Mg}^{2+}$-chelating role [17-20]. Two possible mechanisms proposed for prenyltransferase reactions are (1) sequential ionization-condensation-elimination mechanism where allylic substrate releases its diphosphate to form a carbocation intermediate, which is attacked by IPP, and a proton $\left(\mathrm{H}_{\mathrm{R}}\right.$ for trans-type and $\mathrm{H}_{\mathrm{S}}$ for cis-type) is removed from IPP C2 to form the adduct, and (2) concerted condensation-elimination mechanism where ionization of allylic substrate and condensation of IPP occur simultaneously (Supplementary material: Scheme 1) [21]. FPPs (a short-chain trans-type enzyme) reaction had been shown to proceed through a sequential mechanism [22]. However, the mechanism of cis-prenyltransferases was not clearly determined.

In this paper, we examined the mechanisms of long-chain transOPPs and cis-UPPs, by attempting to trap the farnesyl carbocation 
intermediate from FPP by using a synthetic IPP analogue with bromo to slow down the condensation step. The evidence of different mechanisms for the two types of prenyltransferases was obtained as reported herein.

\section{Materials and methods}

Chemicals. Radiolabeled $\left[{ }^{14} \mathrm{C}\right] \mathrm{IPP}(55 \mathrm{mCi} / \mathrm{mmol})$ and $\left[{ }^{3} \mathrm{H}\right] \mathrm{FPP}$ (17 Ci/mmol) were purchased from Amersham Pharmacia Biotech. Radiolabeled $\left[{ }^{14} \mathrm{C}\right] \mathrm{FPP}(40-60 \mathrm{mCi} / \mathrm{mmol})$ was obtained from American Radiolabeled Chemicals, Inc. Thin layer chromatography (TLC) plates were purchased from Merck. Potato acid phosphatase (2 U/mg) was purchased from Roche Molecular Biochemicals. E. coli UPPs and OPPs were prepared as previously reported $[23,24]$. All reagents and solvents used in the organic synthesis were purchased from Sigma-Aldrich, Acros, and Fluka.

General methods. Proton and carbon NMR spectra are reported in parts per million downfield from internal $\mathrm{Me}_{4} \mathrm{Si}$, and phosphorous spectra in parts per million downfield from external phosphoric acid. NMR spectra were obtained in either $\mathrm{CDCl}_{3}$ or $\mathrm{D}_{2} \mathrm{O}$. Silica gel column chromatography was performed on grade 60,235-400 mesh silica gel (Merck), and TLC was performed on silica gel 60 F-254 glass plates (Merck). Silica TLC plates were visualized under UV light, by iodine, or by dipping in a $10 \%$ solution of phosphomolybdic acid in methanol followed by heating. Yields refer to chromatographically and spectroscopically pure compounds, unless otherwise stated.

Attempt of trapping farnesyl carbocation intermediate in the OPPS and UPPs reactions using radiolabeled FPP. In a reaction mixture containing $5 \mu \mathrm{M}$ OPPs or UPPs, $0.5 \mathrm{mM} \mathrm{MgCl}_{2}, 50 \mathrm{mM} \mathrm{KCl}$ and $0.1 \%$ Triton X-100 in $100 \mathrm{mM}$ Hepes-KOH (pH 7.5) at $25^{\circ} \mathrm{C}, 0.5 \mu \mathrm{M}$ of $\left[{ }^{3} \mathrm{H}\right]$ FPP was added to initiate the enzymatic reaction. A portion of reaction solution ( $33 \mu \mathrm{L}$ ) was withdrawn after $0,5,10,15,20$, 40,60 , and $80 \mathrm{~min}$ and mixed with $67 \mu \mathrm{L}$ of $0.6 \mathrm{~N} \mathrm{NaOH}$ to terminate the enzyme reaction. Octane was utilized to extract $\left[{ }^{3} \mathrm{H}\right] \mathrm{FOH}$ (farnesol) under basic condition if formed, while the substrate $\left[{ }^{3} \mathrm{H}\right] \mathrm{FPP}$ was still in the aqueous phase.

Synthesis of 3-bromo-3-butenyl p-methylbenzenesulfonate (1). Compound 1 was synthesized by following the general procedure of Davission et al. as shown in Scheme 2 (Supplementary material) [25]. $2.53 \mathrm{~g}$ (13.25 mmol) of crystallized $p$-toluenesulfonyl chloride and $1.94 \mathrm{~g}(15.9 \mathrm{mmol})$ of 4 -( $N, N$-dimethy 1 amino)pyridine were dissolved in dichloromethane ( $0.2 \mathrm{M}$ in $p$-toluenesulfonyl chloride) with magnetic stirring under nitrogen. To this solution was added $2.0 \mathrm{~g}$ ( $13.25 \mathrm{mmol}$ ) of 3-bromo-3-buten-1-ol, and the reaction mixture was stirred overnight. The mixture was poured into a 100 -fold excessive volume of hexane, and the resulting precipitate was removed by filtration. The filtrate was concentrated at reduced pressure, and the product was purified by column chromatography to afford $3.23 \mathrm{~g}(80 \%)$ of colorless oil. ${ }^{1} \mathrm{H}$ NMR $\left(400 \mathrm{MHz}, \mathrm{CDCl}_{3}\right) \delta$ $2.47(\mathrm{~s}, 3 \mathrm{H}) 2.76(\mathrm{t}, J=6 \mathrm{~Hz}, 2 \mathrm{H}), 4.21(\mathrm{t}, J=6 \mathrm{~Hz}, 2 \mathrm{H}), 5.50(\mathrm{~s}$, 1H), 5.67 (s, 1H), 7.36 (d, J = 8 Hz, 2H), 7.80 (d, $J=8 \mathrm{~Hz}, 2 \mathrm{H})$.

Synthesis of 3-bromo-3-butenyl diphosphate (Br-IPP) (2). To 3bromo-3-butenyl p-methylbenzenesulfonate $(10 \mathrm{mg}, 0.03 \mathrm{mmol})$ was added $67.7 \mathrm{mg} \quad(0.075 \mathrm{mmol})$ of tris(tetrabutylammonium)hydrogen diphosphate in acetonitrile $(0.5-1.0 \mathrm{M})$ and stirred overnight. The resulting material was converted to the ammonium form with 10 equivalents of resin, and after lyophilization the resulting powder was purified by reversed-phase HPLC on C8 column. Preparative-scale chromatography was performed on Agilent

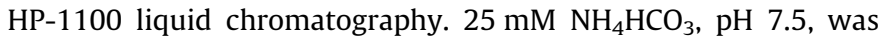
used to dissolve samples and as the aqueous component in reversed-phase HPLC. All solvents were filtered and degassed before use, and samples were passed through a $0.45 \mu \mathrm{m}$ filter before injection. Br-IPP (2) was purified by reversed-phase HPLC on a $250 \times 10 \mathrm{~mm}$ Thermo C8 column and eluted with a linear gradient of $10 \% \mathrm{CH}_{3} \mathrm{CN}$ in $25 \mathrm{mM} \mathrm{NH}_{4} \mathrm{HCO}_{3}$ to $40 \% \mathrm{CH}_{3} \mathrm{CN}$ over $50 \mathrm{~min}$. The final product (2) was obtained in $24 \%$ yield as a white solid. ${ }^{1} \mathrm{H}$ NMR (400 MHz, $\left.\mathrm{D}_{2} \mathrm{O}\right) \delta 2.74(\mathrm{t}, J=6 \mathrm{~Hz}, 2 \mathrm{H}), 4.05$ (dt, $J_{\mathrm{H}, \mathrm{H}}=6.2 \mathrm{~Hz}$, $\left.J_{\mathrm{H}, \mathrm{P}}=7.4 \mathrm{~Hz}, 2 \mathrm{H}\right), 5.51(\mathrm{~s}, 1 \mathrm{H}), 5.75(\mathrm{~s}, 1 \mathrm{H}) ;{ }^{13} \mathrm{C} \mathrm{NMR}(400 \mathrm{MHz}$, $\left.\mathrm{D}_{2} \mathrm{O}\right) \delta 41.46\left(\mathrm{~d}, J_{\mathrm{c}, \mathrm{p}}=7 \mathrm{~Hz}\right), 63.45\left(\mathrm{~d}, J_{\mathrm{c}, \mathrm{p}}=5 \mathrm{~Hz}\right), 119.13,129.61$; ${ }^{31} \mathrm{P}$ NMR (400 MHz, $\left.\mathrm{D}_{2} \mathrm{O}\right) \delta 1.55,-7.83$; HRMS: $\mathrm{m} / \mathrm{z}$ calculated for $\mathrm{C}_{4} \mathrm{H}_{8} \mathrm{BrO}_{7} \mathrm{P}_{2}\left(\mathrm{M}^{+}\right)$308.8934, found 308.8776.

Attempt of trapping farnesyl cabocation intermediate using radiolabeled FPP and Br-IPP. Intermediate trapping in the OPPs and UPPs reactions was attempted in the presence of Br-IPP. In a reaction mixture containing $10 \mu \mathrm{M}$ OPPs or UPPs, $100 \mu \mathrm{M}$ Br-IPP, $0.5 \mathrm{mM}$ $\mathrm{MgCl}_{2}, 50 \mathrm{mM} \mathrm{KCl}$ and $0.1 \%$ Triton X-100 in $100 \mathrm{mM}$ Hepes-KOH ( $\mathrm{pH} 7.5)$ at $25^{\circ} \mathrm{C}, 0.5 \mu \mathrm{M}\left[{ }^{3} \mathrm{H}\right] \mathrm{FPP}$ was added to initiate the enzyme reaction. A portion of reaction solution $(33 \mu \mathrm{L})$ was withdrawn after $0,5,10,15,20,40,60$, and $80 \mathrm{~min}$ and mixed with $67 \mu \mathrm{L}$ of $\mathrm{NaOH}(0.6 \mathrm{~N})$ to terminate the enzyme reaction. Octane was utilized to extract the $\left[{ }^{3} \mathrm{H}\right] \mathrm{FOH}$ resulted from the intermediate if there was, which was quantitated by scintillation counting.

Analysis of reaction intermediate and products by TLC. The reaction condition was $10 \mu \mathrm{M}$ enzyme (OPPs or UPPs), $10 \mu \mathrm{M}\left[{ }^{14} \mathrm{C}\right] \mathrm{FPP}$, $100 \mu \mathrm{M} \mathrm{Br}$-IPP in buffer of $100 \mathrm{mM}$ Hepes-KOH (pH 7.5), $0.5 \mathrm{mM}$ $\mathrm{MgCl}_{2}, 50 \mathrm{mM} \mathrm{KCl}$, and $0.1 \%$ Triton X-100. After incubating for $20 \mathrm{~min}, 100 \mu \mathrm{L}$ reaction mixture was mixed with $200 \mu \mathrm{L} \mathrm{NaOH}$ $(0.6 \mathrm{~N})$ to terminate the enzyme reaction and the $\left[{ }^{14} \mathrm{C}\right] \mathrm{FOH}$ if formed was extracted with equal volume of n-octane (radiolabeled polyprenyl diphosphates were in the aqueous phase). The octane solution after evaporation to reduce volume was spotted on a reversed-phase TLC plate, and then eluted with acetone/water (18:2) for $200 \mathrm{~min}$. The $20 \%$ propanol solution containing $4.4 \mathrm{U} /$
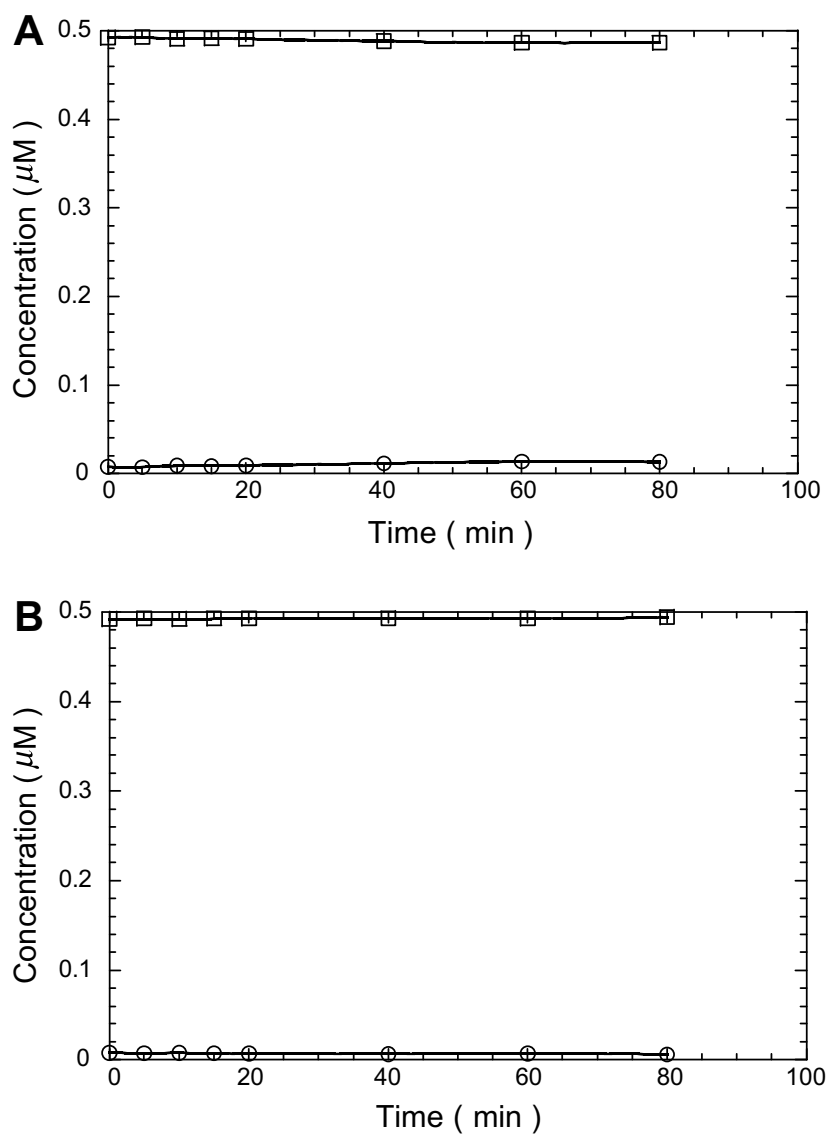

Fig. 1. Time courses of the incubation of $0.5 \mu \mathrm{M}\left[{ }^{3} \mathrm{H}\right] \mathrm{FPP}(\square)$ with $5 \mu \mathrm{M}$ OPPs (A) and UPPs (B) in the absence of Br-IPP. No radiolabeled $\left[{ }^{3} \mathrm{H}\right] \mathrm{FOH}(\mathrm{O})$ extractable by octane was found. 

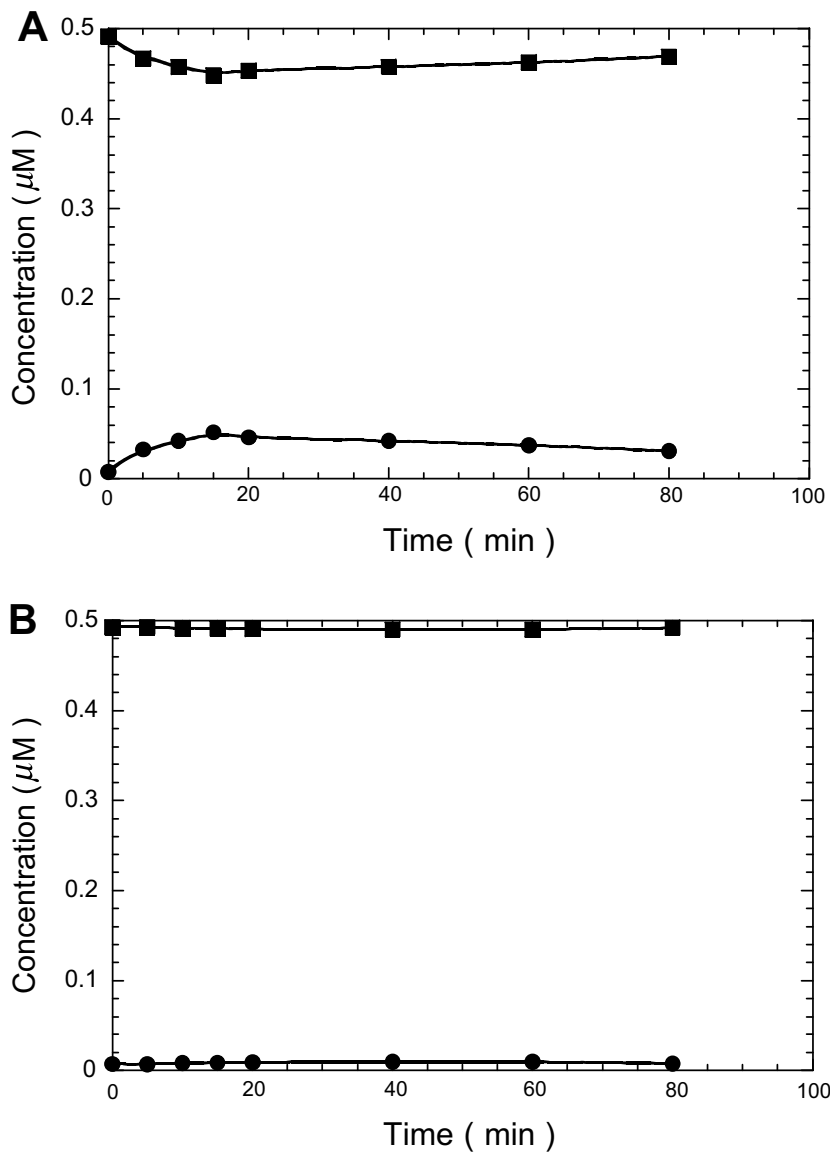

Fig. 2. Attempt of trapping farnesyl carbocation intermediate from $\left[{ }^{3} \mathrm{H}\right] \mathrm{FPP}$ $(0.5 \mu \mathrm{M})$ using Br-IPP $(100 \mu \mathrm{M})$ in $10 \mu \mathrm{M}$ OPPs $(\mathrm{A})$, and UPPs (B) reactions in the time period of $80 \mathrm{~min}$. Radioactivity of $\left[{ }^{3} \mathrm{H}\right] \mathrm{FOH}$ was detected in OPPs reaction mixture extracted with octane, but not in UPPs reaction. The total concentrations of the substrate and the products which remained in the aqueous solution are shown with ( $\boldsymbol{\square})$, whereas the concentrations of intermediate extracted with octane are shown with $(\bullet)$.

$\mathrm{mL}$ acidic phosphatase, $0.1 \%$ Triton $\mathrm{X}-100$, and $50 \mathrm{mM}$ sodium acetate ( $\mathrm{pH} 4.7)$ was used to convert $\left[{ }^{14} \mathrm{C}\right] \mathrm{FPP}$ to $\left[{ }^{14} \mathrm{C}\right] \mathrm{FOH}$ that was used as a standard. The TLC plate with radiolabeled products was analyzed by autoradiography using a bioimaging analyzer (Fujifilm BAS-1500).

\section{Results}

No intermediate was trapped in OPPs and UPPs reactions with only radiolabeled FPP

We first attempted to trap the possible farnesyl carbocation intermediate by incubating $\left[{ }^{3} \mathrm{H}\right] \mathrm{FPP}$ with OPPs or UPPs. After incubation, the mixture was quenched with base and octane was used to extract the $\left[{ }^{3} \mathrm{H}\right] \mathrm{FOH}$ if formed. As shown in Fig. $1 \mathrm{~A}$ and $\mathrm{B}$ for OPPs and UPPs reactions, respectively, no radioactivity could be obtained in the octane layer.

\section{Synthesis of Br-IPP}

The failure of intermediate trapping may be due to the absence of the other substrate IPP. To maximize the possibility of trapping farnesyl carbocation intermediate, we used Br-IPP with an electron-withdrawing bromo group attached to the C3 of IPP to slow down the condensation step by destabilizing the formed carbocat-
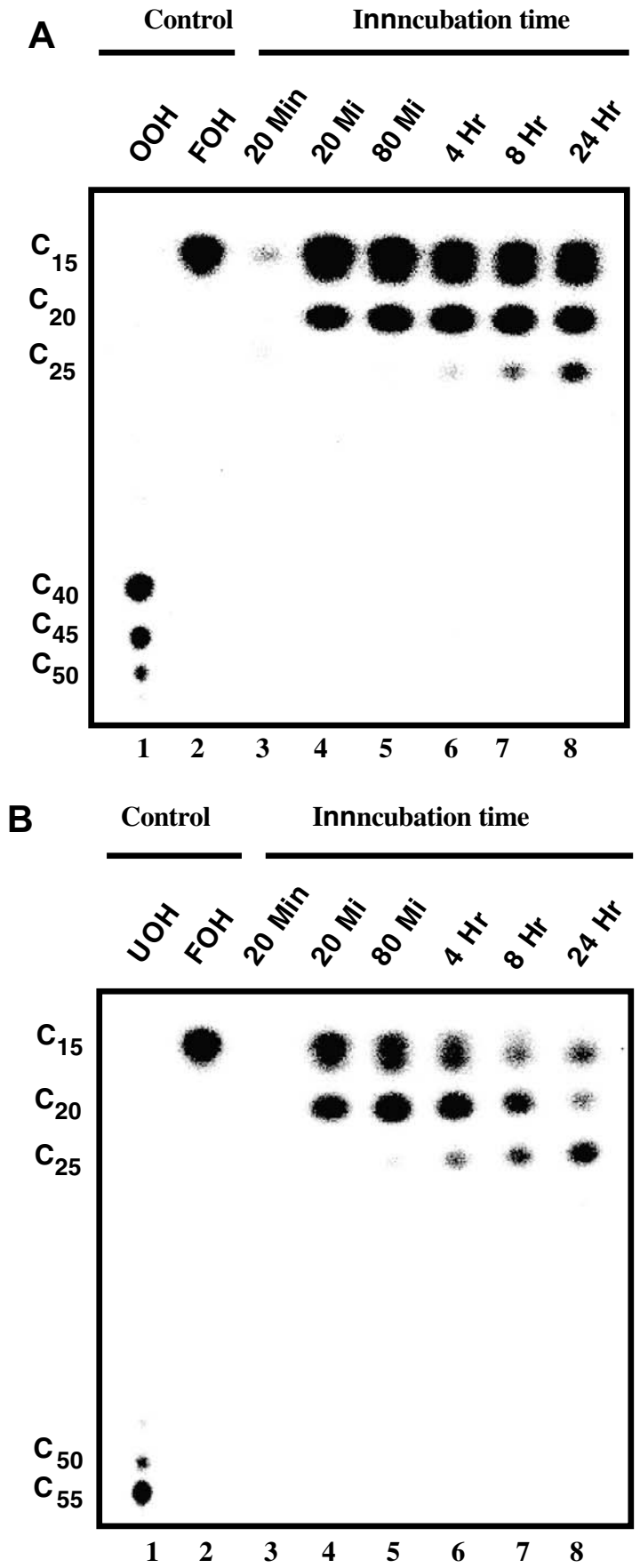

Fig. 3. Analysis of intermediate and products in OPP and UPPs reactions from $20 \mathrm{~min}$ to $24 \mathrm{~h}$. The reaction mixtures contained $10 \mu \mathrm{M}$ OPPs (A), or UPPs (B), $10 \mu \mathrm{M}$ $\left[{ }^{14} \mathrm{C}\right] \mathrm{FPP}$, and $100 \mu \mathrm{M} \mathrm{Br}$-IPP in a buffer of $100 \mathrm{mM}$ Hepes- $\mathrm{KOH}(\mathrm{pH} 7.5), 0.5 \mathrm{mM}$ $\mathrm{MgCl}_{2}, 50 \mathrm{mM} \mathrm{KCl}$, and $0.1 \%$ Triton X-100. (A) The products of OPPs reaction in aqueous solution after $20 \mathrm{~min}$ (lane 4), $80 \mathrm{~min}$ (lane 5), $4 \mathrm{~h}$ (lane 6 ), $8 \mathrm{~h}$ (lane 7), and $24 \mathrm{~h}$ (lane 8) are shown. $\left[{ }^{14} \mathrm{C}\right] \mathrm{FOH}$ extracted with octane after 20 min of reaction is shown in lane 3 as eluted at the same position as the standard (lane 2). (B) The products of UPPs reaction after $20 \mathrm{~min}$ (lane 4), $80 \mathrm{~min}$ (lane 5), $4 \mathrm{~h}$ (lane 6 ), $8 \mathrm{~h}$ (lane 7), and $24 \mathrm{~h}$ (lane 8 ) are shown. No $\left[{ }^{14} \mathrm{C}\right] \mathrm{FOH}$ was detected in the UPPs reaction (lane 3 ).

ion. For the synthesis of Br-IPP, a commercially available 3-bromo3-buten-1-ol was converted to the tosylate species $\mathbf{1}$, which was then reacted with the diphosphate salt to yield Br-IPP (2) (Supplementary material: Scheme 2). This substrate analogue showed a significantly reduced activity as shown below. 

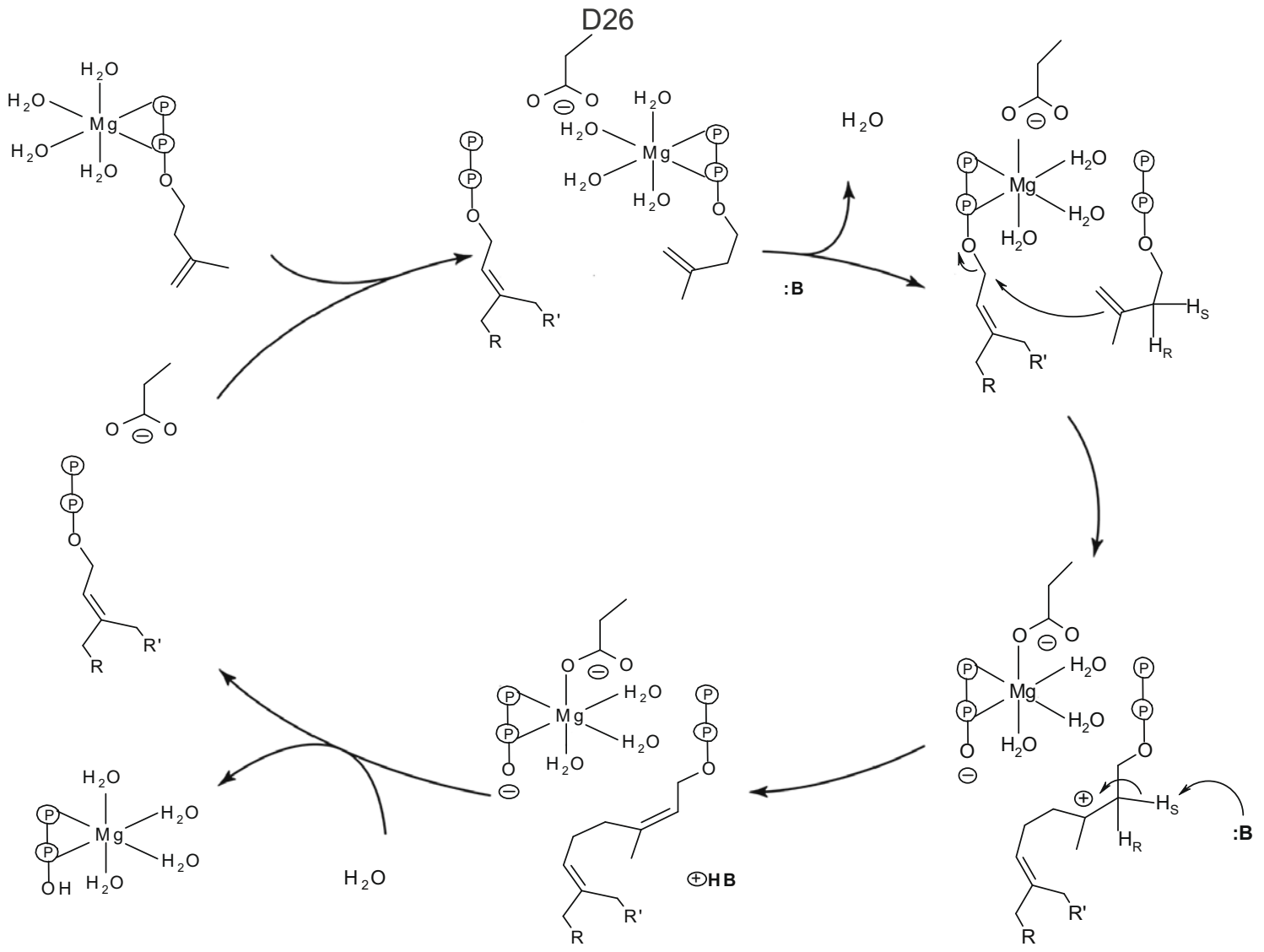

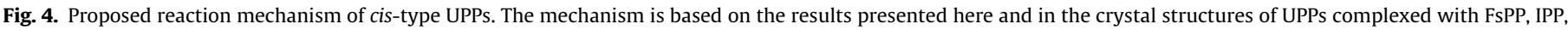

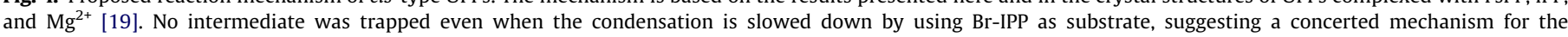
condensation reaction.

Farnesyl carbocation intermediate was trapped in OPPs reaction, but not in UPPs reaction with radiolabeled FPP and Br-IPP

For trapping farnesyl carbocation intermediate, $\operatorname{Br}-\mathrm{IPP}(100 \mu \mathrm{M})$ was added with the $\left[{ }^{3} \mathrm{H}\right] \mathrm{FPP}$ substrate $(0.5 \mu \mathrm{M})$ into the reaction mixtures of OPPs and UPPs, respectively, each containing $10 \mu \mathrm{M}$ enzyme. In the presence of Br-IPP, radioactivity associated with $\left[{ }^{3} \mathrm{H}\right] \mathrm{FOH}$ resulted from the farnesyl carbocation intermediate in the reaction of OPPs was detectable in the octane layer (Fig. 2A). The maximal quantity of the intermediate was observed after 15min single-turnover reaction. However, the radiolabeled intermediate was not detectable for UPPs under the same condition (Fig. 2B).

\section{Reaction intermediate and products analyzed by TLC}

To show the radioactivity in the octane layer was really from $\mathrm{FOH}$ in the OPPs reaction, the products of $10 \mu \mathrm{M}\left[{ }^{14} \mathrm{C}\right] \mathrm{FPP}$ and $100 \mu \mathrm{M} \mathrm{Br}$-IPP with $10 \mu \mathrm{M}$ enzyme from $20 \mathrm{~min}$ to $24 \mathrm{~h}$ in the aqueous layer and octane layer were analyzed using TLC (Fig. 3A). For comparison, the reactions products of UPPs in the aqueous layer and octane layer analyzed by TLC are shown in Fig. 3B. ${ }^{14} \mathrm{C}$-radiolabeled substrate was used here for bioimaging analysis. As revealed in these Figures, the reactions became remarkably slower when using Br-IPP as an alternative substrate (lanes 4-8 show the progress of the reactions with time in the aqueous layer). Only two Br-IPP condensation reactions occurred in $24 \mathrm{~h}$ and the reaction products had not reached $\mathrm{C}_{40}$ and $\mathrm{C}_{55}$ as compared to the standards in lane 1 . At the 20 -min time point in the middle of reactions, the $\left[{ }^{14} \mathrm{C}\right] \mathrm{FOH}$ in the octane layer was detectable in the OPPs reaction (lane 3 of Fig. 3A), which was eluted at the same position as the standard (lane 2), but not in the UPPs reaction (lane 3 of Fig. 3B).

\section{Discussion}

Both OPPs and UPPs catalyze multiple IPP condensation reactions, leading to long-chain products. With normal substrate IPP, no farnesyl carbocation can be trapped in both reactions. However, when the condensation is slowed down by Br-IPP, the farnesyl carbocation intermediate is formed in the OPPs reaction, giving direct proof for the sequential ionization-condensation-elimination mechanism for trans-prenyltransferases. In contrast, no such intermediate was trapped in UPPs reaction under the same reaction conditions with $\mathrm{Br}$-IPP, indicating it may undergo a concerted reaction. As illustrated in Fig. 4, FPP binds to UPPs first and then IPP as a $\mathrm{Mg}^{2+}$-complex binds to the active site with D26, and then the $\mathrm{Mg}^{2+}$ is transferred to the diphosphate of FPP as previously demonstrated [20]. However, as shown in this study, the diphosphate of FPP is released and IPP attacks the farnesyl carbocation intermediate simultaneously without accumulation of the intermediate. Since Br-IPP can slow down the UPPs reaction, a cationic character on C3 of IPP must develop after the condensation (also shown in Fig. 4). Elimination of the $\mathrm{H}_{\mathrm{S}}$ proton leads to a new cis-double bond to neutralize the carbocation.

Unlike UPPs, the active site of OPPs bears negative charges near the C1 of FPP, which may induce the formation of the farnesyl carbocation intermediate. As shown in the crystal structures of FPPs, 
the side chain oxygen atoms of Thr203 and Gln241 and the main chain carbonyl of Lys202 are oriented with their negative dipoles directed toward the allylic carbocation-binding site [16]. The derived information of intermediate as presented in this study is useful for drug design. In fact, the nitrogen atom in the FPPs inhibitors (e.g. zoledronate) next to the bisphosphonate group was designed to mimic the cationic character of the intermediate [26]. However, in UPPs, this strategy may not be useful without definite formation of the carbocation intermediate. As shown by the QSAR analysis based on the crystal structures of the bisphosphonate inhibitors binding with UPPs, the binding affinity is solely determined by the bisphosphonate head and the hydrophobic tail [27]. Taken together, our data enhance our understanding on the mechanisms of two different prenyltransferases, particularly UPPs, and facilitate the drug discovery against this enzyme.

\section{Acknowledgments}

This work was supported in part by a grant from National Science Council of Taiwan.

\section{Appendix A. Supplementary data}

Supplementary data associated with this article can be found, in the online version, at doi:10.1016/j.bbrc.2008.12.061.

\section{References}

[1] H.V. Thulasiram, H.K. Erickson, C.D. Poulter, Chimeras of two isoprenoid synthases catalyze all four coupling reactions in isoprenoid biosynthesis, Science 316 (2007) 73-76.

[2] K. Ogura, T. Koyama, H. Sagami, Polyprenyl diphosphate synthases, Subcell. Biochem. 28 (1997) 57-87.

[3] P.H. Liang, T.P. Ko, A.H. Wang, Structure, mechanism and function of prenyltransferases, Eur. J. Biochem. 269 (2002) 3339-3354.

[4] B.A. Kellogg, C.D. Poulter, Chain elongation in the isoprenoid biosynthetic pathway, Cur. Opin. Chem. Biol. 1 (1997) 570-578.

[5] K. Ogura, T. Koyama, Enzymatic aspects of isoprenoid chain elongation, Chem. Rev. 98 (1998) 1263-1276.

[6] C.D. Poulter, H.C. Rilling, The prenyl transfer reaction. Enzymic and mechanistic studies of the $1^{\prime}-4$ coupling reaction in the terpene biosynthetic pathway, Acc. Chem. Res. 11 (1978) 307-313.

[7] K. Okada, M. Minehira, X. Zhu, K. Suzuki, T. Nakagawa, H. Matsuda, M. Kawamukai, The ispB gene encoding octaprenyl diphosphate synthase is essential for growth of Escherichia coli, J. Bacteriol. 179 (1997) 3058-3060.

[8] K. Okada, K. Suzuki, Y. Kamiya, X. Zhu, S. Fujisaki, Y. Nishimura, T. Nishino, T. Nakagawa, M. Kawamukai, H. Matsuda, Polyprenyl diphosphate synthase essentially defines the length of the side chain of ubiquinone, Biochim. Biophys. Acta 1302 (1996) 217-223.

[9] C.M. Allen, Purification and characterization of undecaprenylpyrophosphate synthetase, Methods Enzymol. 110 (1985) 281-299.

[10] X. Fang, K. Tiyanont, Y. Zhang, J. Wanner, D. Boger, S. Walker, The mechanism of action of ramoplanin and enduracidin, Mol. Biosyst. 2 (2006) 69-76.
[11] S. Peukert, Y. Sun, R. Zhang, B. Hurley, M. Sabio, X. Shen, C. Gray, J. Dzink-Fox, J. Tao, R. Cebula, S. Wattanasin, Design and structure-activity relationships of potent and selective inhibitors of undecaprenyl pyrophosphate synthase (UPPS): tetramic, tetronic acids, and dihydropyridine-2-ones, Bioorg. Med. Chem. Lett. 18 (2008) 1840-1844.

[12] N. Shimizu, T. Koyama, K. Ogura, Molecular cloning, expression, and purification of undecaprenyl diphosphate synthase. No sequence similarity between E- and Z-prenyl diphosphate synthases, J. Biol. Chem. 273 (1998) 19476-19481.

[13] C.M. Apfel, B. Takacs, M. Fountoulakis, M. Stieger, W. Keck, Use of genomics to identify bacterial undecaprenyl pyrophosphate synthetase: cloning, expression, and characterization of the essential uppS gene, J. Bacteriol. 181 (1999) 483-492.

[14] L.C. Tarshis, P.J. Proteau, B.A. Kellogg, J.C. Sacchettini, C.D. Poulter, Regulation of product chain length by isoprenyl diphosphate synthases, Proc. Natl. Acad. Sci. U S A 93 (1996) 15018-15023.

[15] R.T. Guo, C.J. Kuo, C.C. Chou, T.P. Ko, H.L. Shr, P.H. Liang, A.H. Wang, Crystal structure of octaprenyl pyrophosphate synthase from hyperthermophilic Thermotoga maritima and mechanism of product chain length determination, J. Biol. Chem. 279 (2004) 4903-4912.

[16] D.J. Hosfield, Y. Zhang, D.R. Dougan, A. Broun, L.W. Tari, R.V. Swanson, J. Finn, Structural basis for bisphosphonate-mediated inhibition of isoprenoid biosynthesis, J. Biol. Chem. 279 (2004) 8526-8529.

[17] M. Fujihashi, Y.W. Zhang, Y. Higuchi, X.Y. Li, T. Koyama, K. Miki, Crystal structure of cis-prenyl chain elongating enzyme, undecaprenyl diphosphate synthase, Proc. Natl. Acad. Sci. U. S. A. 98 (2001) 4337-4342.

[18] T.P. Ko, Y.K. Chen, H. Robinson, P.C. Tsai, Y.G. Gao, A.P. Chen, A.H. Wang, P.H. Liang, Mechanism of product chain length determination and the role of a flexible loop in Escherichia coli undecaprenyl-pyrophosphate synthase catalysis, J. Biol. Chem. 276 (2001) 47474-47482.

[19] S.Y. Chang, T.P. Ko, P.H. Liang, A.H. Wang, Catalytic mechanism revealed by the crystal structure of undecaprenyl pyrophosphate synthase in complex with sulfate, magnesium, and triton, J. Biol. Chem. 278 (2003) 29298-29307.

[20] R.T. Guo, T.P. Ko, A.P. Chen, C.J. Kuo, A.H. Wang, P.H. Liang, Crystal structures of undecaprenyl pyrophosphate synthase in complex with magnesium, isopentenyl pyrophosphate, and farnesyl thiopyrophosphate: roles of the metal ion and conserved residues in catalysis, J. Biol. Chem. 280 (2005) 2076220774.

[21] C.D. Poulter, D.M. Satterwhite, Mechanism of the prenyl-transfer reaction. Studies with (E)- and (Z)-3-trifluoromethyl-2-buten-1-yl pyrophosphate, Biochemistry 16 (1977) 5470-5478.

[22] C.D. Poulter, J.C. Argyle, E.A. Mash, Letter: prenyltransferase. New evidence for an ionization-condensation-elimination mechanism with 2-fluorogeranyl pyrophosphate, J. Am. Chem. Soc. 99 (1977) 957-959.

[23] J.J. Pan, S.T. Chiou, P.H. Liang, Product distribution and pre-steady-state kinetic analysis of Escherichia coli undecaprenyl pyrophosphate synthase reaction, Biochemistry 39 (2000) 10936-10942.

[24] J.J. Pan, T.H. Kuo, Y.K. Chen, L.W. Yang, P.H. Liang, Insight into the activation mechanism of Escherichia coli octaprenyl pyrophosphate synthase derived from pre-steady-state kinetic analysis, Biochim. Biophy. Acta 1594 (2002) 6473.

[25] V.J. Davisson, A.B. Woodside, T.R. Neal, K.E. Stremler, M. Muehlbacher, C.D. Poulter, Phosphorylation of isoprenoid alcohols, J. Org. Chem. 51 (1986) 47684779.

[26] M. Goffinet, M. Thoulouzan, A. Pradines, I. Lajoie-Mazenc, C. Weinbaum, J.C. Faye, S. Seronie-Vivien, Zoledronic acid treatment impairs protein geranylgeranylation for biological effects in prostatic cells, BMC Cancer 6 (2006) 60 .

[27] R.T. Guo, R. Cao, P.H. Liang, T.P. Ko, T.H. Chang, M.P. Hudock, W.Y. Jeng, C.K. Chen, Y. Zhang, Y. Song, C.J. Kuo, F. Yin, E. Oldfield, A.H. Wang, Bisphosphonates target multiple sites in both cis- and trans-prenyltransferases, Proc. Natl. Acad. Sci. U S A 104 (2007) 10022-10027. 